\title{
Assessing the Gas Market Potential in India
}




\section{About KAPSARC}

The King Abdullah Petroleum Studies and Research Center (KAPSARC) is a non-profit global institution dedicated to independent research into energy economics, policy, technology and the environment across all types of energy. KAPSARC's mandate is to advance the understanding of energy challenges and opportunities facing the world today and tomorrow, through unbiased, independent, and high-caliber research for the benefit of society. KAPSARC is located in Riyadh, Saudi Arabia.

This publication is also available in Arabic.

\section{Legal Notice}

(C) Copyright 2020 King Abdullah Petroleum Studies and Research Center ("KAPSARC"). This Document (and any information, data or materials contained therein) (the "Document") shall not be used without the proper attribution to KAPSARC. The Document shall not be reproduced, in whole or in part, without the written permission of KAPSARC. KAPSARC makes no warranty, representation or undertaking whether expressed or implied, nor does it assume any legal liability, whether direct or indirect, or responsibility for the accuracy, completeness, or usefulness of any information that is contained in the Document. Nothing in the Document constitutes or shall be implied to constitute advice, recommendation or option. The views and opinions expressed in this publication are those of the authors and do not necessarily reflect the official views or position of KAPSARC. 


\section{Key Points}

his workshop gathered over 20 energy and policy experts on October 6, 2019 to discuss the outlook for the natural gas sector in India and how the country can increase the share of gas in its energy mix. The discussions focused on policy options to reverse stalling gas demand, how India should take advantage of weak global liquefied natural gas market conditions, and India's aspirations for its gas market in the context of past experiences and potential for change. The key findings from the workshop include:

Considerable skepticism remains about the cost competitiveness of gas, especially in the power sector. As a result, a strong policy push is required to raise the share of gas in India's energy mix.

Low-cost coal and ever-cheaper renewable energy are squeezing out gas as a primary fuel for power generation. However, gas can increase the stability and flexibility of the power sector, improve energy security, and reduce emissions when compared with coal.

As the Indian economy continues to expand, increasing the gas supply - and access to it - can help meet rising energy needs, advance energy efficiency and reduce the economy's environmental footprint. In particular, shifting from high carbon fuels to gas will be key to improving air quality and help to demonstrate India's commitment to mitigating climate change.

Policy support in the form of price rationalization, infrastructure development, and internalizing environmental costs will be crucial for the growth of the gas sector in India. 


\section{Summary}

ndia faces a pressing energy shortage. Despite rapid economic development, a large section of the population has little or no access to electricity, while the cost, reliability and availability of power constrain growth and investment in key sectors. As a result of this unmet demand, India has the potential to become one of the world's largest consumers of natural gas. The commodity offers the government a cost-effective and environmentally sound answer to the country's rising energy needs - yet the gas sector has struggled since 2010. The main obstacles to increasing the share of gas in the energy mix are a slowdown in domestic production, pricing and allocation issues, inefficient regulatory practices, and inadequate infrastructure.

Pricing mechanisms and cost are the key determinants of gas demand in India for both existing consumers in industry and power, and emerging consumers such as the city gas sector. The government has attempted reforms to make price regulation more transparent by linking wholesale gas prices to select international markets. However, these efforts have added complexity and uncertainty to price formation because the pricing components use international benchmarks that have limited similarity to the Indian market. Consequently, India's upstream gas pricing mechanisms need to be reformed and rationalized. New pricing regimes based on the opportunity costs of imported gas and alternative fuels for new production facilities may address some of these concerns.

The taxation regime is a core pricing-related issue impacting the retail cost of gas. Despite its significantly lower carbon footprint, gas is effectively taxed at a higher rate than coal due to taxes applied throughout the value chain, making the former uneconomical for power generation and other important sectors. To make gas competitive, the government should reform fiscal and tax policies so that the cumulative tax burden across the entire gas value chain, from production or import to consumption by the end user, is appropriate.

Other pricing challenges extend to pipeline infrastructure and transmission tariffs. Many experts believe that adequate gas infrastructure is the key prerequisite for demand creation. However, pipeline development has failed to keep pace with growth in gas demand, and numerous pipeline proposals have been deemed financially unfeasible because of a perceived lack of demand or unfavorable economics. In addition, the additive nature of India's pipeline tariff system pushes up retail prices, making gas uncompetitive with alternative power sources.

For gas to achieve substantial growth as a share of India's overall energy mix, power generation is by far the most critical sector. Yet the combination of current energy market dynamics and unfavorable domestic regulations have made the fuel uncompetitive with coal and, increasingly, renewables. As state governments resist raising electricity rates for politically sensitive groups of consumers, such as the domestic and agriculture segments, the high cost of electricity production will only exacerbate the sector's dependence on government subsidies. Accordingly, the national government should better align its energy policies with its long-term goals for the country's power generation sector and energy mix. The authorities should decide whether gas will play more of a secondary or a central role in the country's power mix, with due consideration given to its environmental benefits over coal. Policymakers should also take into account that while industry, transport and households are all potential growth markets for gas in India, each brings its own set of challenges. 


\section{Background to the Workshop}

$\mathrm{n}$ India, the share of natural gas in the energy mix is shrinking, even as the country's demand

for energy increases. The government has called for greater utilization of the fuel to help meet the needs of the rapidly growing economy in a more environmentally friendly manner but struggled to support its targets for gas with effective policy.

Saudi Arabia faces a similar challenge in increasing the share of gas in its own energy mix. Despite the government's efforts to reduce the economy's dependence on oil and slash carbon emissions, it has proven difficult to restructure the power generation sector, which remains heavily dominated by oil. Thus, policy recommendations for supporting gas consumption in India can provide insights for energy policy design in Saudi Arabia as well.

The workshop sought to answer three main research questions to assess the potential of the gas market in India and identify strategies to increase the share of gas in the energy mix.
1. What are the fundamental market and policy design barriers to faster growth in gas consumption in India, and to what extent can these can be overcome?

2. What untapped opportunities exist for increasing the gas supply in the country, from both domestic production and imports, and what are the potential constraints?

3. What lessons in policy and market design does India's experience offer to Saudi Arabia, especially given similar industrialization targets? 


\section{Structural Factors and Policy Issues Affecting the Gas Sector in India}

ndia has long stressed the importance of natural gas in meeting the country's growing energy

needs in an environmentally sustainable manner. For example, Hydrocarbon Vision 2025, an energy policy blueprint released by the government in 1999, projected that gas would account for $20 \%$ of the country's energy consumption by 2025 . Yet as of 2018 , the fuel accounts for just $6 \%$ to $7 \%$ of India's overall energy mix. This is despite growing concern over air quality problems, and the role gas could play in supporting national renewable energy targets by providing support for intermittencies in renewable electricity generation.

To address this shortfall, the government has committed to increase the share of gas in its energy mix to $15 \%$ by 2030 , and aims to double domestic gas production by 2022.
The authorities have moved away from revenue sharing and liberalized marketing and pricing regulations, as well as adding a 'single window' clearance system for all exploration and production activities. Under the new Open Acreage policy, 32 new blocks have been awarded. India is also actively seeking to promote unconventional gas production from coal bed methane, gas hydrates, and shale. However, the international oil majors have yet to make any significant investments into the upstream sector.

On the demand side, India has moved ahead in promoting gas consumption in city gas networks, including for transport, domestic and small urban industries. The government has also endorsed liquefied natural gas (LNG) as a road transport fuel and is conducting relevant pilot studies.

Figure 1. Share of gas compared with policy targets (1990-2018).

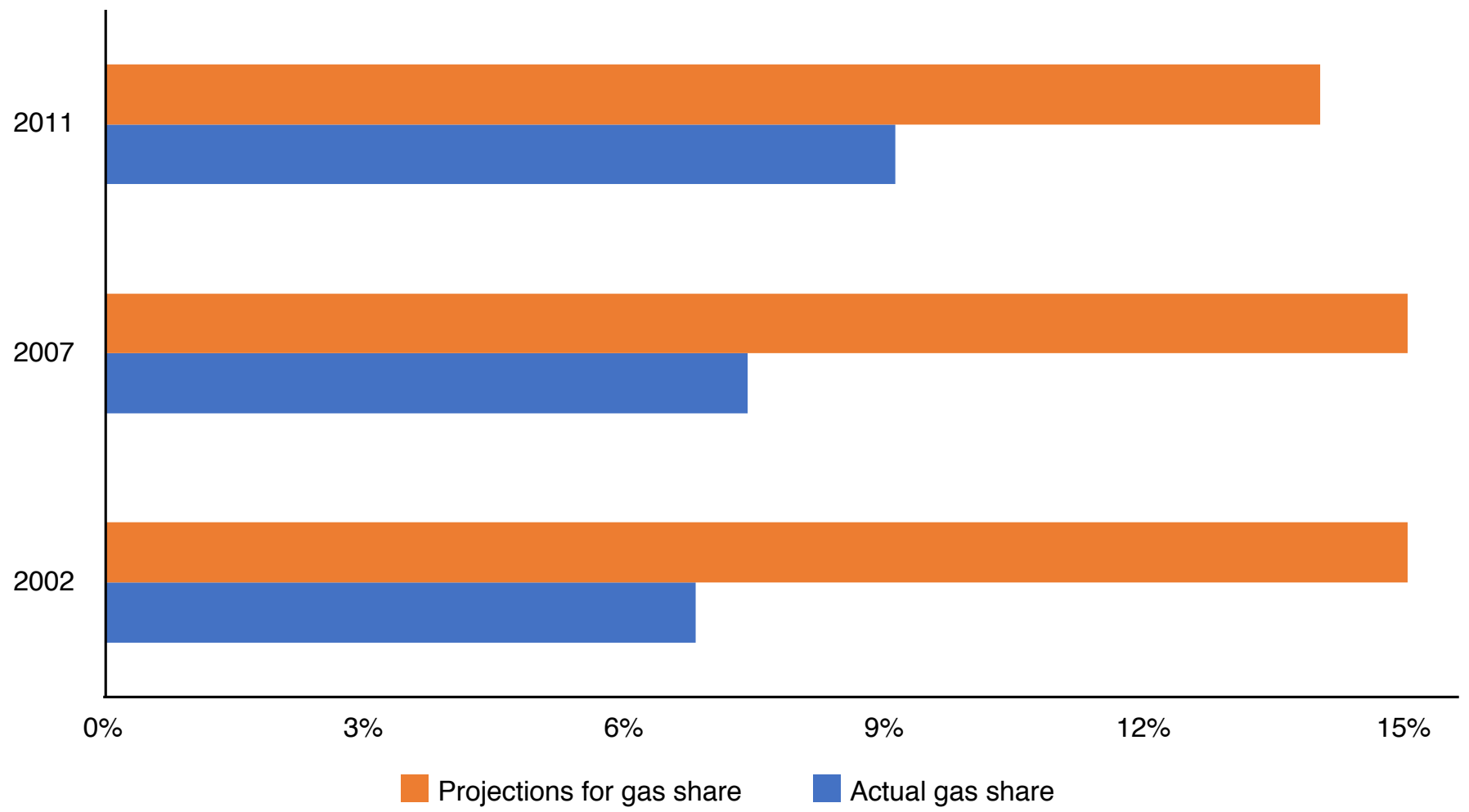

Sources: BP Statistical Review 2019; Niti Aayog; KAPSARC. 
As shown in Figure 1, above, and discussed earlier, India's past targets for gas utilization have not been realized.

Pricing mechanisms and cost are the key factors that determine gas demand in India. Relatively mature (such as power and fertilizer) and emerging (such as city gas) sectors are both considered very price-sensitive in India. Further, reform measures introduced in 2012-2014 that link upstream prices with international markets had the unintended consequence of increasing the complexity and uncertainty of price formation. The pricing formula implemented was intended for more developed economies, and the international benchmarks it uses have limited similarity to the Indian market.

Inconsistent fiscal policy also undermines New Delhi's goal of increasing gas utilization. A range of taxes levied along the gas value chain, especially on pipelines, result in the fuel being taxed at a higher overall rate than coal, despite the environmental advantages of the former.
The messy tax regime also complicates pricing and compliance. Beyond taxation, the broader regulatory and policy landscape is weak and overly complex, particularly for price setting and licensing. This has led to several jurisdictional conflicts including litigation between the state government of Gujarat and the Union government regarding jurisdiction over gas resources.

Finally, infrastructure development continues to face a classic 'chicken-and-egg' problem. Many experts believe that creating adequate gas infrastructure - known as the 'carrier first' strategy - is the key prerequisite for demand creation. Thus, building infrastructure is key to promoting demand growth. However, numerous pipeline projects have failed to move forward because of a perceived lack of demand or unfavorable economics. 


\section{Growth of Gas Demand in India: Aspirations and Feasibility}

ndia's energy mix remains dominated by coal, while gas plays a secondary role (in 2018, coal accounted for over $70 \%$ of total energy consumption compared with just $6 \%$ for gas). Domestic and global energy market dynamics make coal highly competitive in terms of cost and availability, while the domestic coal industry also increases energy security and local economic activity associated with India's coal supply. Meanwhile, renewable energy is becoming cheaper and India has plans to add 175 gigawatts (GW) of renewable electricity generation capacity by 2022 .

Nevertheless, gas can play a significant role in electricity generation and help reduce system-wide carbon emissions. Gas power can not only help meet India's surging baseload demand; it can also increase the flexibility and reliability of the overall power generation system. This will partly be determined by the pace at which new city gas distribution infrastructure is built out. Gas can also provide a substitute for liquid fuels. As a power source, gas emits a far lower volume of greenhouse gases than coal does, even taking into account the carbon dioxide and methane released during production, transport and processing. In 2018, globally, gas on average emitted $50 \%$ less than coal per unit of electricity generated, and 33\% less per unit of heat used in industry and buildings.
Outside of power generation, gas consumption can be increased in industry (including fertilizer production, already a major gas user) and the residential and transportation sectors. Gas also offers an efficient alternative to coal in the iron and steel industries. The new city gas distribution licenses awarded by the government of India since 2018 underlined India's ambitions to extend the gas grid, although a host of licensing and financing challenges remain before these plans can be realized. With gas prices less than US $\$ 7.5$ per million British thermal units ( $\$ / M M B t u)$, gas is also cost competitive compared with coal. These sectors appear better able than gas-fired power plants to absorb higher-priced gas. However, in some other applications such as textiles and paper, the transition to gas from coal will lead to a higher cost of production.

The example of China suggests that initiatives to improve urban air quality and shift the industrial sector toward lighter manufacturing can increase industrial consumption of gas. However, this required a concerted policy push by Beijing to build out gas infrastructure. In industrial applications, enforcement of stricter emissions control standards could push private companies to direct their new capacity investments toward gas. In addition, an increased focus on energy efficiency would also help make the economic case for gas even apart from environmental considerations. 
Figure 2. Users of domestic gas versus LNG, by gas-consuming sector in India (annual averages 2015-2018).

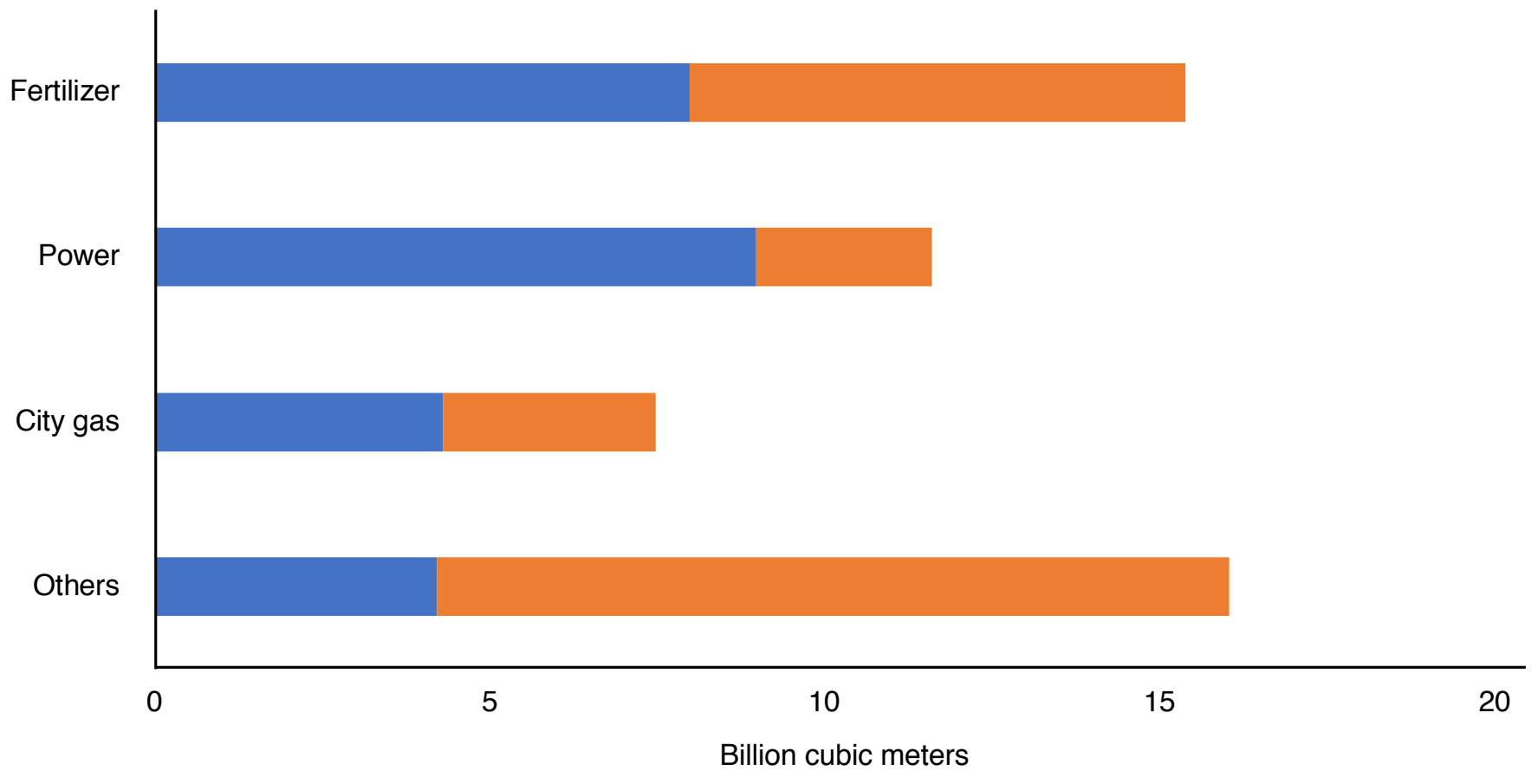

Domestic gas

LNG

Source: IEA. 


\section{Pricing and Optimization of LNG Supplies}

ricing mechanisms and access to infrastructure are the main hurdles for gas demand growth in India. Some experts call for the establishment of a domestic spot market for gas to catalyze demand. Because India is a net importer of natural gas, the logical price formation principle is import parity, which means in this context that the price of gas delivered to end-users should be the LNG import price plus delivery costs on the pipeline network, provided that third-party access (TPA) is granted. However, the government sets the price using the Administered Pricing Mechanism, which factors in a six-month lag on global benchmark prices. This in effect may not be ideal for exploration and production companies that have investment horizons of between 10 and 15 years. Another obstacle is the monopolization of the gas midstream sector, where a sole company has full control of the natural gas transportation network in certain regions. The company may not allow TPA and may charge heavy tariffs on natural gas deliveries.

The inefficiencies currently facing the gas sector in India are reminiscent of those seen in the coal sector. Authorities delinked coal from international prices in order to facilitate economic growth by reducing energy costs, and only a single state company was allowed to mine and sell coal. However, when the government allowed private companies into the market in 1993, many rushed in to exploit pricing arbitrage opportunities between the domestically controlled prices and open international markets. This demonstrates the importance of institutional and regulatory frameworks as gas industry pricing mechanisms are restructured to ensure that gas comprises at least $15 \%$ of the primary energy mix.
As a net importer of natural gas, India has benefited from declining global LNG prices over the last four years. The drop in oil prices during this period has meant that oil-linked LNG contracts are more affordable. In addition, spot LNG prices have also fallen, increasing spot purchases. However, the widening difference between spot LNG prices and oil-linked contract prices have caused many in the sector to argue that long-term oil-linked contracts should not be in a country's portfolio. Officials in India have once again called for the renegotiation of existing long-term contracts, which potentially causes LNG suppliers to view India as an unreliable market for long-term contracts.

The results of an economic modeling analysis show that India can benefit from transitioning all future purchases to the spot market and entering no more long-term contracts. According to the model, this cuts India's average import prices by $\$ 1.50 /$ MMBtu from a business-as-usual scenario - a very compelling argument for ending long-term contracts. However, without such contracts in place, sellers are not committed to supplying the Indian market, and there may be shortages during tight market conditions, as analysts predict will occur in the mid2020s. Thus policymakers should determine the best mix of long-term contracts and spot market purchases based on both energy security and cost advantages. 


\section{Closing: Is India the Next China?}

ill gas consumption in India follow a similar upward trajectory as that seen in China? Several developments in India suggest that this could be possible. Deteriorating air quality is the most impactful issue analogous to the Chinese experience, as the government, private sector and population increasingly seek ways to reduce air pollution. Another key similarity is the emergence of a middle class able to afford higher energy consumption.
Renewable energy is expected to play a bigger role in India's energy mix as costs decline. However, renewable energy and natural gas should be viewed not only as competitors but also as complementary solutions to meeting India's rapidly growing demand for electricity and reducing carbon emissions. In China, renewable energy and gas consumption are both increasing, helping to supply the country's rising energy needs without directly hampering each other. However, environmental pressure will not be enough - the government must design and implement effective fiscal, pricing and infrastructure policies for India to achieve its gas consumption targets. 


\section{About the Workshop}

APSARC organized this workshop as part of the project Assessing the Gas Market

Potential in India, which aims to identify strategies to increase the share of natural gas in India's energy mix. Held on October 6, 2019, the workshop brought together over 20 energy experts from industry and research institutes to discuss policy factors and market configurations that will determine the future of the gas sector in India.

\section{List of Participants}

Raja Al Marzouki - Economics Professor, Diplomatic Studies Institute

Sarah Alotaibi - Researcher, King Faisal Center for Research \& Islamic Studies

Subhomoy Bhattacharjee - Consultant, Research and Information Systems

Danila Bochkarev - Senior Fellow, East West Institute

Kaushik Deb - Research Fellow, KAPSARC

Shahid Hasan - Research Fellow, KAPSARC

Eaman Iman - Advisor, Ministry of Energy

Jonathan H. Elkind - Fellow and Senior Research Scholar, Columbia University

Hideki Matsubara - Chief Representative, Diamond Gas International (Mitsubishi)
Coby van der Linde - Director, Clingendael International Energy Program

Nitin Maurya - Programme Associate (Alternative Fuels), Council on Energy, Environment and Water

Maxime Schenckery - Director of the Center for Energy Economics and Management, IFP School

Rami Shabaneh - Senior Research Associate, KAPSARC

Aurangzeb Qureshi - Senior Energy Analyst, International Energy Forum (IEF)

Abhinav Trivedi - Young Professional, Niti Aayog

Colin Ward - Director, KAPSARC

Vitaly Yermakov - Senior Research Fellow, Oxford Institute for Energy Studies

Peter Zeniewski - Gas Lead, World Energy Outlook 
Notes

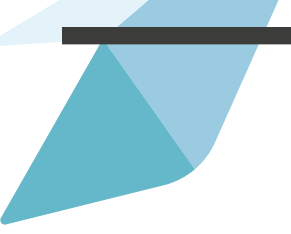




\section{About the team}

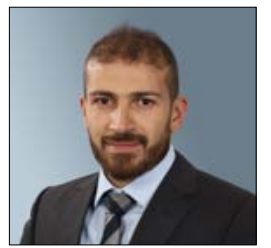

\section{Rami Shabaneh}

Rami is a senior research associate focusing on global gas and liquids markets. He has more than 10 years of research and industry experience in energy market analysis. He holds an M.Sc. in Sustainable Energy Development from the University of Calgary.

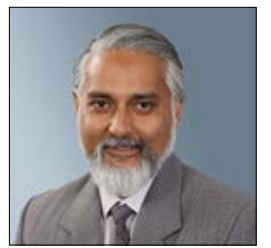

\section{Kaushik Deb}

Kaushik is a research fellow in the Markets and Industrial Development program. He is an applied economist who previously worked in the Economics team at BP, leading the analysis of global gas markets and macroeconomic developments in the Asia Pacific region. His earlier roles include policy research and advocacy on infrastructure and environmental economics issues at IDFC. Kaushik has also guided and implemented research in applied economics at TERI University, and undertaken the role of program director of the university's MBA programs.

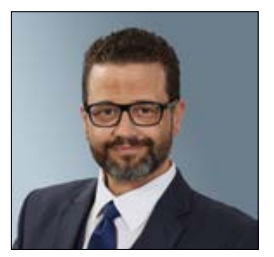

\section{Colin Ward}

Colin is the interim director of the Markets and Industrial Development program. He has worked in the energy industry for 10 years in various capacities, including seismic field work, refinery design and consulting for major international oil companies and national oil companies worldwide. Colin plays a major role in several KAPSARC projects, primarily focusing on cost estimation for energy projects and environmental impacts of the global energy industry.

\section{About the Project}

India's gas consumption has grown more slowly than its overall energy consumption, leading to a loss of market share for gas in the national energy basket. This contrasts sharply with government targets laid out in various policy statements calling for the increased use of gas in India to meet its rapidly rising energy demand efficiently and in an environmentally friendly manner. This project aims to derive lessons from policy and market designs in countries that have grown their domestic gas markets, especially those with similar industrialization and environmental targets to India. 
INAPSARC

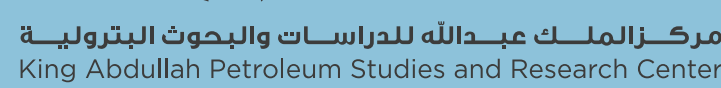

www.kapsarc.org 